\title{
The Construction of Entrepreneurship Education Model in Chinese Universities Against the Background of "Internet plus"
}

\author{
Jingmin Zhang*, Liwei Cui \\ School of History, Culture and Tourism \\ Liaoning Normal University \\ Dalian, China
}

\begin{abstract}
In the context of "Internet plus", based on the useroriented, open, shared and collaborative internet thinking, the integration between internet and various industries is becoming a research hotspot. Based on the neo-constructivism, in order to develop the entrepreneurship education in Chinese universities, this paper constructs the "one center and four goals" entrepreneurship education model against the background of "Internet plus". One Center means student-centered, while Four Goals, that are, the integration of entrepreneurship education and professional education, the integration of the real and virtual entrepreneurial education environment, the wisdom of teaching methods and learning methods in entrepreneurship education and the diversification of entrepreneurial education teachers. This paper puts forward the development trend of learning personalization, teaching intelligence, resource optimization and global cultural penetration of entrepreneurship education, so as to promote the better development of entrepreneurship education in China.
\end{abstract}

Keywords-Internet plus; Chinese Universities; Entrepreneurship Education; Model

\section{INTRODUCTION}

Entrepreneurship education as an educational idea was first formally proposed by Colin Bol in 1989. Entrepreneurship education is based on the educational concept of "opening, creating, exploring, and integrating", with "learning by making" as the main learning method, training compound talents with innovative spirit, entrepreneurial awareness and ability as the educational purpose, achieving individual creativity and value are educational goals. "Internet plus education" is a new education paradigm created by using Internet technology, adhering to the characteristics of Internet opening, sharing, reconstruction, and cross-space and time, such as the application of MOOC, micro-classes, and flipped classrooms. In the process of entrepreneurship education, universities connect the real world and the virtual world through Internet technology in order to integrate teachers, students, and educational resources into an organism, build a smart learning environment, conduct interactive teaching, reconstruct teacher-student relationship and encourage students to learn creatively. Based on "Internet plus", the thesis discusses the model of entrepreneurship education in universities from the perspectives of entrepreneurial education concepts, content, platforms, methods and teaching faculties.

\section{LITERATURE REVIEW}

\section{A. The Connotation of Neo-Constructivism}

In 2011, the first phase of the CETA Educational Technology Salon was held in Guangdong, and Wang Zhuli proposed "New Constructionist" [1]. Neo-constructivism is proposed in response to the characteristics of learning in the Internet age. It takes knowledge innovation as the ultimate goal and emphasizes the integration of learning, application and innovation into an organic whole. The core idea can be summarized by "situation, search, selection, writing, communication, innovation, meaning construction" [2]. Scenarios are important for learning. Search is a prerequisite for learning in the Internet age. Selection is the continuation of search. Writing is thinking, from "Integrated Writing" to "Personality Rewriting" and finally to "Creative Reconstruction". Cyclic ascent process, communication includes collaboration and conversation. Collaboration refers to communication in action, conversation refers to verbal communication, innovation emphasizes the continuous updating of individual knowledge systems. Meaning construction refers to make knowledge innovation while understanding and applying knowledge.

\section{B. The Main Points of Neo-Constructivism}

\section{1) The Neo-Constructivism's view of knowledge}

a) The three-level structure theory of knowledge: Neoconstructivism believes that knowledge is divided into three levels, namely primary structure (perceptual knowledge), secondary structure (rational knowledge) and tertiary structure (association). Knowledge consists of tertiary structure, and the three levels are closely connected, constitute a complete knowledge system and can not be replaced by each other. The three-level structure is the process from diffusion to convergence then to divergence (as shown in figure 1).

This work was sponsored by Liaoning Humanities and Social Sciences Planning Fund Project (L19BJY012) 


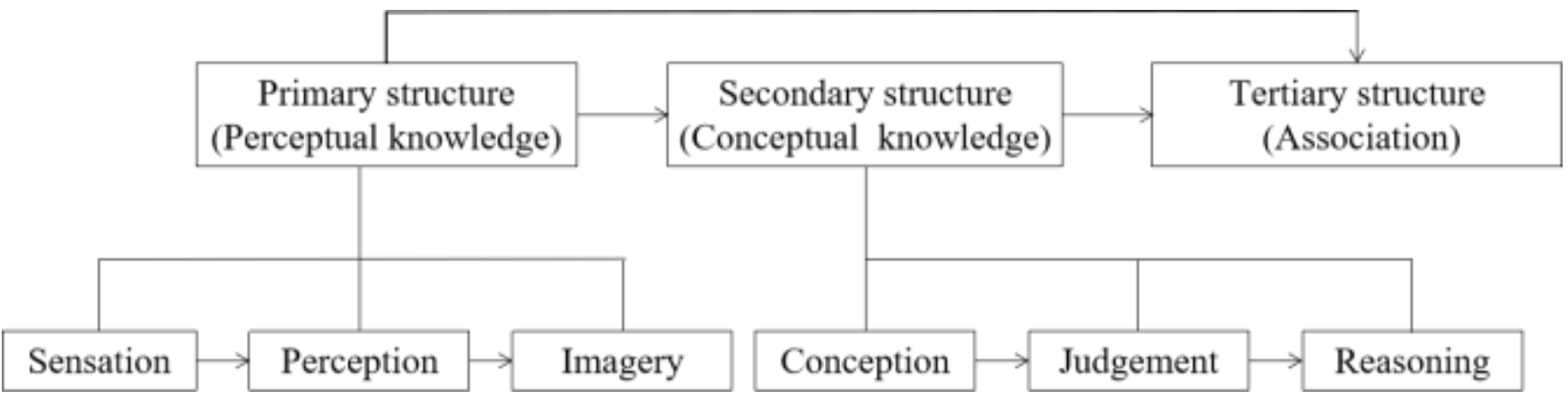

Fig. 1. Diagram of the tertiary structure of knowledge

b) The "graft" theory of knowledg: The "grafting" of knowledge refers to the process of integrating specialized and structured knowledge with secondary structure knowledge in the learner's cognitive system under the guidance of teachers. Its ultimate goal is to achieve knowledge innovation. Knowledge "graft" not only needs to connect with secondary structure knowledge, but also needs the foundation of primary structure knowledge. The process of knowledge "grafting" includes three aspects of docking, integration and innovation, as shown in Figure 2. In the process of docking, teachers may adopt the teaching method to the basic and structurally complete knowledge, while adopt the inquiry-discovery teaching method to the cutting-edge, open and structurally loose knowledge. Neo-constructivism advocates equal emphasis on traditional and open teaching methods.

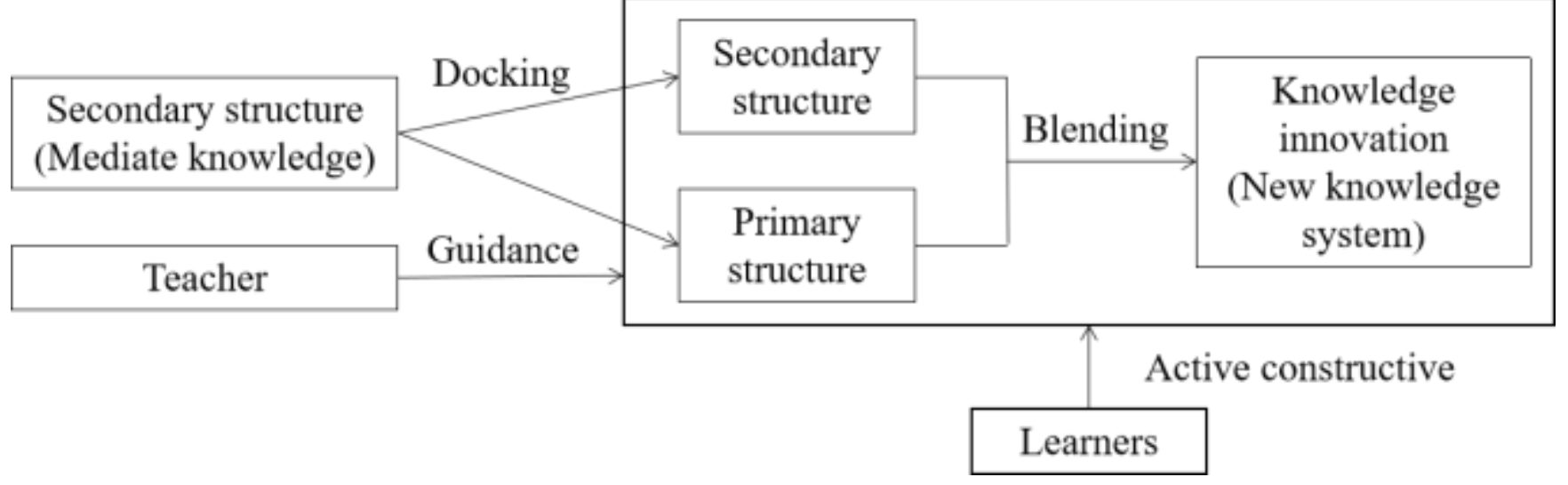

Fig. 2. Diagram of "grafting" knowledge process

\section{2) Neo-Constructivism's view of learning}

Neo-constructivism puts forward the learning strategy of small deposits towards lump withdrawal, which refers to the inclusive thinking of different knowledge and ideas in the era of web-based learning, so as to realize the integration and meaning construction of fragmented knowledge processing, as shown in figure 3. From "integrable ware writing" to "personalized rewriting", then to "creative reconstruction", it is a cycle process, and the end of each cycle is the beginning of another cycle, so the cycle spirals up. Among them, there is also a circular process between any two stages, and each stage communicates and cooperates with the outside world to constantly update the learners' knowledge system. The way of small deposits towards lump withdrawal is a process from dispersion to convergence, which has the characteristics of dimensionality reduction.

3) The Neo-Constructivism's view of teaching

Neo-constructivism believes that "self-grafting" is the key of learning in the net era. "self-grafting" refers to taking the self as the core, searching and selecting the information you need, thinking independently and sharing and communicating with others, so that the individual knowledge system can be constantly updated and meaning construction can be carried out actively. Teachers should not only "graft" knowledge into students' knowledge system, but also teach students how to "graft" themselves, that is how to search, choose, think, write and communicate. 


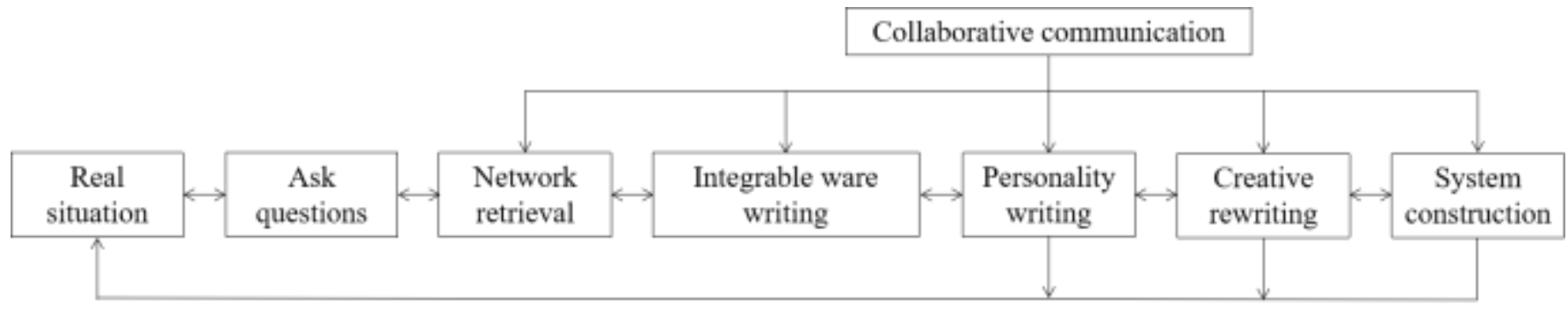

Application test

Fig. 3. Diagram of Neo-constructivism learning process

\section{THE MODE OF ENTREPRENEURSHIP EDUCATION IN ChInese COLLEGES AgAinst THE BACKGROUND OF "INTERNET PLUS"}

Adhering to the concept of "Internet plus Education", based on internet thinking with user-oriented, open, sharing, cooperation, across time-space and neo-constructivism view of knowledge learning and teaching, this paper builds a entrepreneurship education model of "one center and four objectives". "one center" means student-centered; "four goals", that is, the integration of entrepreneurship education and professional education, the integration of the virtual and real environment of entrepreneurship education, the intelligence of entrepreneurship education teaching and learning methods, and the diversification of entrepreneurship education teachers (as shown in figure 4 and figure 5).

"Internet plus Entrepreneurship Education", on the basis of the combination of virtual and real entrepreneurship education environment, adheres to the educational concept of studentcentered education as the core, takes the organic integration of entrepreneurship education and professional education as the platform, takes a diversified team of teachers as the assistant, by means of intelligent teaching and learning methods, cultivates compound talents with innovative spirit, entrepreneurial quality, entrepreneurial thinking and entrepreneurial ability. The entrepreneurship education model of "one center and four objectives" embodies the characteristics of individualization, openness, sharing, mixing and diversification of entrepreneurship education.

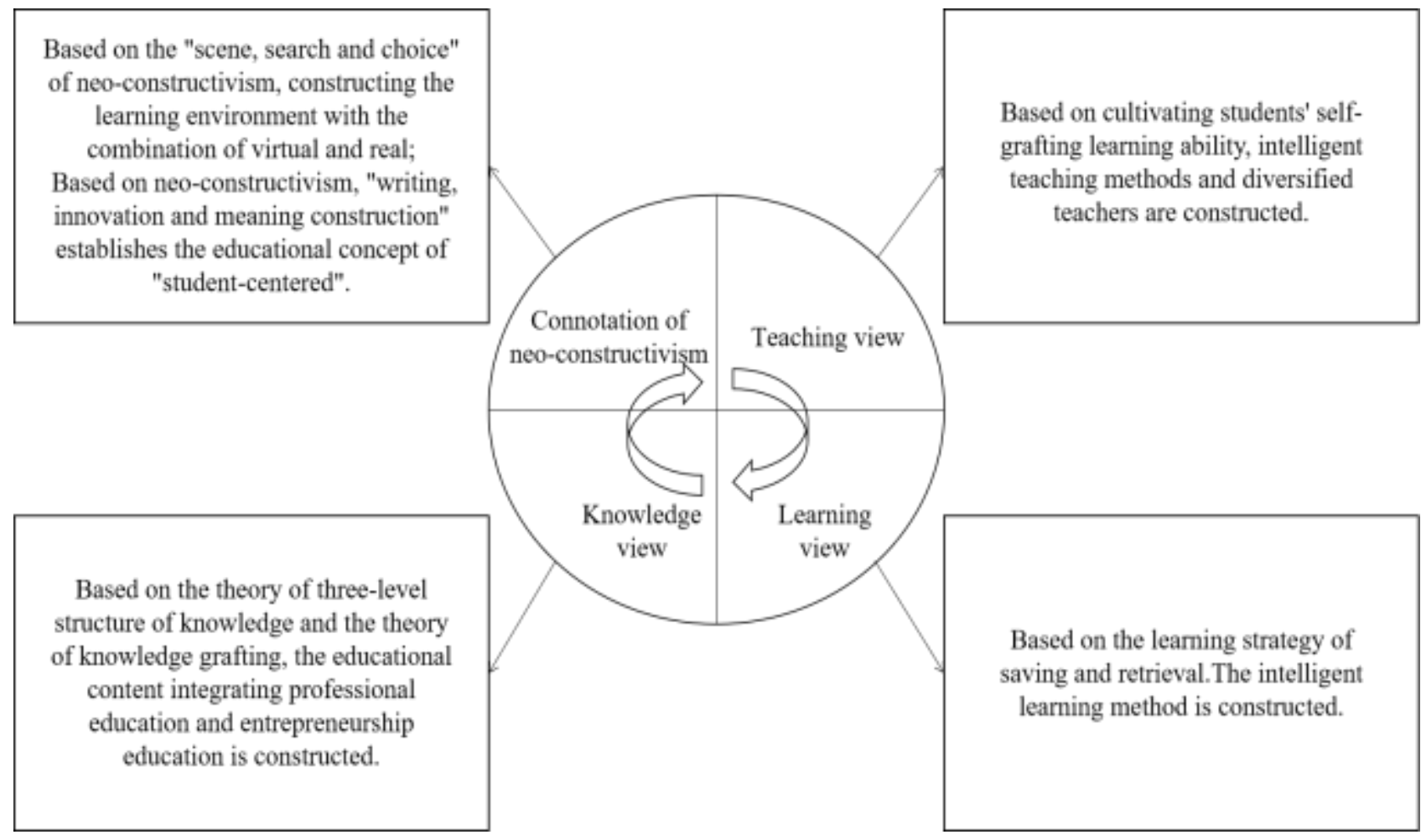

Fig. 4. The Entrepreneurship Education Model based on Neo-Constructivism 


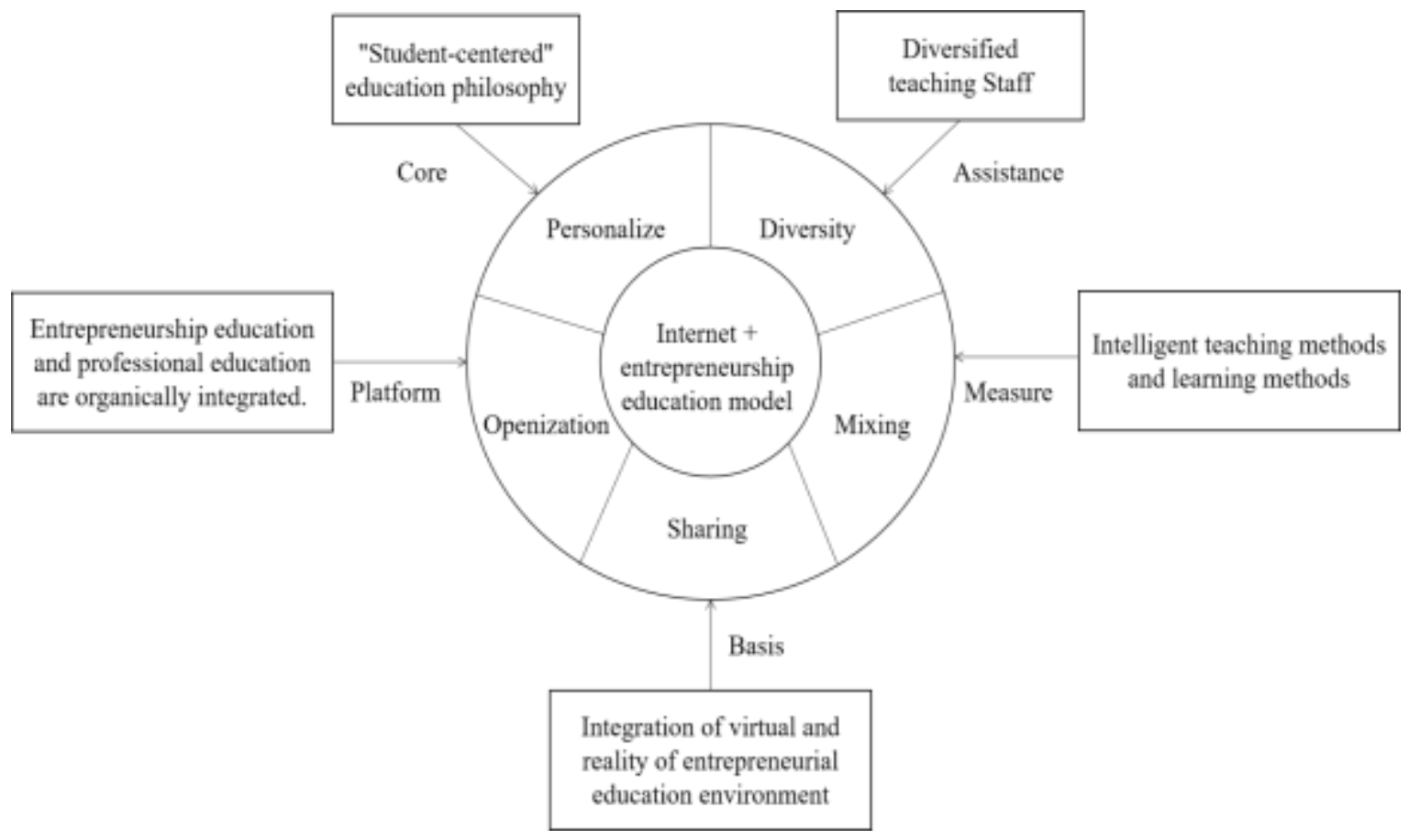

Fig. 5. The "Internet plus Entrepreneurship Education" model frame

\section{ThE PRACTICAL PATH OF ENTREPRENEURShIP EDUCATION MODEL}

\section{A. Form a Student-centered Concept of Entrepreneurship Education}

Neo-constructivism holds that writing, innovation and meaning construction should be based on individual characteristics. Internet thinking takes users as the core to meet the needs and experience of users. Universities should regard students as users, aim to meet the needs of students, and persist in taking students as the center in the process of education. Entrepreneurship education should also take students as the main body, stimulate their entrepreneurial consciousness and cultivate innovative entrepreneurial ability according to their individual characteristics [4].

First of all, according to the "user-oriented" internet thinking and the personalized characteristics of neoconstructivism, universities should form a "student-centered" concept of entrepreneurship education and take students as service objectives, change the traditional "teaching paradigm" to "learning paradigm" and encourage students to become "free" learners. "Freedom" means "self-oriented learning". With the help of the internet, students can improve their ability of self-analysis, self-evaluation and self-management, set learning goals independently, establish learning models, and adjust learning progress, so as to complete autonomous learning.

Secondly, based on neo-constructivism, "Internet plus Entrepreneurship Education" will reconstruct the relationship between teachers and students and form a new educational ecology of openness, sharing and cooperation. The development of the Internet will form a new type of teacher- student relationship, which teachers and students can share and innovate knowledge and become the creators of knowledge together.

Finally, "Internet plus Entrepreneurship Education" will promote students' deep learning. Bloom divides the learners' understanding of knowledge into six levels: memorization, understanding, application, analysis, evaluation and creation, then divides the six goals into two levels: superficial learning and deep learning. Superficial learning points to memorization, understanding and application, while deep learning points to analysis, evaluation and creation. Internet plus Entrepreneurship Education aims to make students change from superficial learning to deep learning, from primary cognitive level to advanced cognitive level, and finally to the creative level [5].

\section{B. Integration of Entrepreneurship Education and Professional Education}

Neo-constructivism advocates that learners' interests and problem-solving needs should be taken as the center, information should be searched and selected, knowledge should be reorganized across borders, self-meaning should be constructed, personal knowledge system should be constantly updated, and cobweb knowledge structure should be established. Entrepreneurship education should cultivate students' innovative thinking, entrepreneurial spirit and entrepreneurial ability, so that they can seize opportunities, make scientific and wise decisions and innovate constantly in a complex environment. In order to achieve this goal, entrepreneurship education should take professional education as the platform and train innovative talents on this platform. Therefore, entrepreneurship education and professional education should be integrated. This kind of integration will 
make the entrepreneurial thought fully infiltrate into the actual teaching of professional education, innovate the curriculum content, reorganize the educational structure, and form a new educational paradigm, so as to train students to become both solid professional knowledge and compound talents with entrepreneurial spirit and ability. With the help of internet technology, entrepreneurship education and professional education can be integrated to form a circular chain of knowledge dissemination, innovation and application, and improve students' practical ability, innovative ability and entrepreneurial skills [5].

Firstly, the cultivation of talents should be student-centered, using internet technology to serve students in all directions. Cultivate students not only with excellent professional skills, but also with innovative spirit and creative ability.

Secondly, in the content of professional courses, the universal courses and heartbeat courses of entrepreneurship plus specialty combining theory and practice should be constructed, and the "heartbeat courses" should be implemented on the basis of universal courses. Universal course is a course of basic knowledge and professional knowledge. Heartbeat course is a personalized and selective course based on students' hobbies and individual differences.

Thirdly, in terms of practical activities, students will be trained to master comprehensive practical skills with internet technology in class and with entrepreneurial practical activities outside the class such as internet plus entrepreneurship competition.

Fourth, the teaching location can adopt the $1+\mathrm{N}$ model, such as in classrooms, experimental bases, enterprise units, dormitories, libraries and other locations. For example, the use of telepresence technology can achieve "face-to-face" communication, allowing two or more remote classrooms to be presented in real time and integrated with local classrooms in an interactive classroom mode. Such a multi-site teaching model can deepen students' knowledge construction, promote professional education to be open and re-creating and integrate entrepreneurship education into professional education.

\section{Create a Virtual and Real Learning Environment}

In the era of web-based learning, aiming at the complexity and fragmentation of information, Neo-constructivism puts forward that learners should search and select information based on problems, so as to integrate learning, application and innovation. Therefore, the Internet has become a necessary tool for students to learn. "Internet plus Education" can overcome the limitation of time and space, construct an interactive virtual learning resource space of sharing, communication, interaction and cooperation, realize education sharing and knowledge sharing. Against the background of "Internet plus", entrepreneurship education in universities should create a learning environment that combines virtual and reality, online and offline seamlessly, so that students can learn, apply and innovate knowledge more deeply in the environment of the combination of virtual and reality.

First, universities can establish a virtual network interactive platform, which can become a real place for students, teachers and students to interact and share knowledge. Through this platform, individuals are connected to provide personalized and diversified services for individuals to meet the needs of students with different learning directions and learning levels.

Second, universities can build real interactive platforms and combine virtual reality technology on these platforms to enable students to learn creatively in the process of experience, exploration and sharing. For example, through the establishment of college students' innovative and entrepreneurial workshops, industrial parks, micro-classes etc., achieve "learning by doing", to provide entrepreneurial communication space for students of different majors, and improve participation and interaction. At the same time, artificial intelligence technology can be used as students' entrepreneurial assistant in these real entrepreneurial environments, and fragmented knowledge can be sorted out, screened and analyzed to solve the problems encountered by students in the process of starting a business.

Third, universities can use artificial intelligence AR/VR and other technologies to simulate the real scene and establish a virtual learning environment for human-computer interaction. For example, a virtual simulation training platform is introduced in Chengdu University of Technology to move enterprises into the school, by which students can play different roles and simulate the work flow of enterprises. It not only increases students' real feelings for a deeper understanding what they have learned, but also makes students realize their own shortcomings in training, so as to quickly improve their ability.

\section{Use Intelligent Teaching Method and Learning Method}

Neo-constructivism advocates to establish an individual personalized knowledge system which center on learners' interests and problem-solving needs. In view of this, teachers should cultivate students' ability of "self-grafting" and the learning strategy of small deposits towards lump withdrawal. Therefore, in the process of implementing entrepreneurship education, both teachers' teaching methods and students' learning methods should be student-centered and provide services for students' all-round development. Based on Internet technology, teachers need to use intelligent teaching method, while students need to use intelligent learning method to fundamentally change the traditional way of "teaching" and "learning", so as to promote students' creation progress and guide students to construct individual knowledge system.

"Intelligent teaching methods" means that teachers regard students as complete people, fully consider individual differences, pay attention to individual all-round development, and make use of internet technology to provide personalized learning services for individuals. It includes on-screen teaching, project-oriented learning, debating learning, game learning and differentiated teaching. "Intelligent learning methods" is that students make use of internet technology, take "creation" as the starting point and destination, carry out self-reflection, selfanalysis, set self-learning goals, establish learning models, adjust learning progress, self-evaluation and self-management, carry out self-driven learning to improve learning enthusiasm and self-cognitive ability. In a word, teachers can flexibly use 
intelligent teaching method according to the content of entrepreneurship education, while students can actively use intelligent method in the process of entrepreneurship learning to improve the participation and effect of entrepreneurship education.

\section{E. Training a Diversified Contingent of Teachers in Entrepreneurship Education}

Neo-constructivism holds that the primary task of teachers is to cultivate students" ability of "self-grafting", that is, to guide students how to search, choose, think, write and communicate. Therefore, teachers should not only have rich professional and entrepreneurship education knowledge, but also have certain information technology literacy.

Teacher is the key factor to guide and promote the healthy development of entrepreneurship education in universities. The overall level of teachers in universities is closely related to the development of entrepreneurship education. Universities should take "going out and come in" as the guiding concept to build a diversified team of teachers.

First, universities should implement the combination of full-time and part-time teachers. In addition to recruiting excellent professional teachers, it is also necessary to employ entrepreneurs or venture capitalists with rich entrepreneurial experience outside the school as part-time mentors, to create a diversified team of teachers.

Second, universities should train teachers of entrepreneurship education in an all-round way. Excellent entrepreneurial teachers are selected to participate in all kinds of online and offline training, further studies, seminars and so on, so as to improve the theoretical level of teachers. Universities should support teachers to use internet technology to carry out entrepreneurial teaching and scientific research, participate in entrepreneurial projects jointly organized by schools and enterprises, and enrich teachers' practical experience. Then universities can make use of the existing curriculum platforms such as MOOC courses, excellent courses and open courses to integrate excellent resources, share more entrepreneurship courses, and exchange entrepreneurship education.

Third, universities should set up a team of entrepreneurial teachers across disciplines, profession and departments, define the division of labor, learn from each other and study jointly entrepreneurship education so as to provide accurate help for students [6].

\section{CONCLUSION}

Internet plus Entrepreneurship Education does not use the internet as a tool, but integrates organically the internet with entrepreneurship education. Based on the theory of neoconstructivism, Chinese universities implement the entrepreneurship education model of "one center and four goals" by giving full play to the multiplication effect of internet technology, promote everyone to become a creator of knowledge and tap the individual's innovative ability. Entrepreneurship education using Internet technology will show the development trend of intelligence, openness, socialization and globalization.

\section{ACKNOWLEDGMENT}

This paper was sponsored by Liaoning Humanities and Social Sciences Planning Fund Project "Research on the Mode, Performance and Path of Service Innovation of Liaoning Tourism Industry from the Perspective of Integration of Tourism, Culture and Science Industries" (L19BJY012). Also thanks to Teaching Reform Research Project of Liaoning Normal University "Innovation Research and Practice of the Training Model of Applied Talents Majored in Tourism under Industry-education Integration and Collaborative Education" (2-4). Really appreciate their supports.

\section{REFERENCES}

[1] Wang Zhuli. New Constructivism: Theoretical System and Innovational Practices[J]. Journal of Distance Education,2012,30(06):3-10. (In Chinese).

[2] Wang Zhuli, Li Xiaoyu, Lin Jin. Smartphones and the "Internet + Class":A New Thinking and New Pattern of Information Technology Integrated into Curriculum[J].Journal of Distance Education, 2015,33(04):14-21. (In Chinese).

[3] Wan Liyong, Kang Cuiping. Internet plus Maker Education: Construction of the New Ecology for Innovation and Entrepreneurship Education in Universities [J]. Research in Educational Development, 2016,36(07):59-65. (In Chinese).

[4] Zhu Zhiting, New Developments of Smarter Education: From Flipped Classroom to Smart Classroom and Smart Learning Space[J]. Open Education Research,2016(2):18-27. (In Chinese)

[5] Zeng Mingxing, Huang Wei. Research on the Integration Path Between Maker Education and Professional Education from the Perspective of Internet Plus[J]. Modern Distance Education Research,2017(03):67-75. (In Chinese).

[6] LIU Yu ,YU Xin, XU Hongzhi. Innovation Education against the background of Public Business Innovation: Practice, Effect and Machanism[J]. Modern Educational Technology,2015(11):106-112. (In Chinese). 